\title{
The Importance of Hip-Hop Events and their Impact on Event Management in Dubai
}

\author{
${ }^{1}$ Ali Hakim Zadeh, ${ }^{2}$ Daniel Marco-Stefan Kleber \\ ${ }^{1,2}$ Academic Department of Business Administration, \\ MODUL University Dubai, UAE
}

E-mail: 16010062@modul.ac.ae

\begin{abstract}
The world market is becoming increasingly saturated and differentiation has become essential. An assessment needs to be conducted on the usage of marketing and event management tools in major hip hop events and their effectiveness in providing economic benefit. This research study will utilize both primary and secondary data sources, mainly primary, in the form of interviews with industry professionals and experts in Dubai's event field, to obtain an accurate perspective. Understanding the importance of hip hop and its economic impact will help to open up a new perspective to current research streams in the field. The research will focus on three key areas through analyzing Dubai's hip hop events significances: the city's ability to differentiate itself through hip hop events, the ability to attract major artists and audience from the region and the benefits for the event management sector. Development of surrounding businesses, employment opportunities, culture awareness and crowd attraction are potential outcomes which can be expected from the above presented events in Dubai. The study aims at supporting a successful initiation and execution of hip-hop events which will give Dubai an economic edge against its competitors in this growing sector.

Keywords: Culture, Dubai, Events, Event Management, Hip-Hop
\end{abstract}

\begin{tabular}{ll}
\hline JEL & $:$ M3 \\
DOI & $: 10.24002 /$ kinerja.v22i2.2391
\end{tabular}

Received : 08/01/2019 Reviewed: 08/16/2019 Final Version: 09/25/2019

\section{INTRODUCTION}

Events and concerts are a possibility for participants to display their talents or showcase a new idea, perspective or invention. Big occasions are used by government and other entities to stir business activity in the region. Dubai has established itself as one of the major destinations for events, specifically, in the genre of Hip-Hop. 
Hip-Hop is "stylized rhythmic music that commonly accompanies rap" (Webster, n.d.). It has an electronic backing and originates from United States' Black and Hispanic community and culture. It has become a worldwide cultural phenomenon and has impacted Dubai, especially the large international community of youngsters. In the middle east, Dubai is known for hosting major events, including Hip Hop. The economic and cultural advancements that branch from hosting an event allow for the continuing transformation of the city (Bureau International des Expositions, n.d.).

The world market is becoming increasingly saturated and differentiation has become essential. For example, tourism makes a large part of Dubai's economy, however, other destinations are rising that may provide a similar experience to what Dubai has to offer. Events provide an opportunity to showcase Dubai and make it an ideal event destination. This makes event management a big part of the city's economic sector. Dubai authorities continuously strive to adopt innovation to give the city an edge (Geronimo, 2018).

It can be seen from their commitment to expos, technology and artificial intelligence, and sustainability. Many famous rappers and artists have performed in Dubai which attracts people from other parts of the Middle East. For example, Jason Derulo, a famous hip hop and R\&B artist, will be performing at Global Village (Coughlin, 2018). One main reason for his appearance is most likely to attract more crowd to the park for event participants and organizers. The aim of this research is to assess the essential aspects of hip hop in Dubai and its event management impact. It's imperative to form areas that promote individuals to come to participate (Hunt, 2018).

It is the responsibility of artists to bring people together, which give hip hop great credibility in a fast-moving city like Dubai. It is important to know if major events boost the number of visitations and the societal development leading to the increased popularity of the location. Also, the assessment must be done on what event management and marketing tools are being used in major hip hop events and their effectiveness in providing economic benefit. There are limited studies on this topic because Hip Hop events are specific occurring in select cities with the infrastructural, audience, and economic provisions.

The research study will utilize both primary and secondary sources to obtain an accurate perspective. The efforts of Dubai's businesses and authorities can give a clear indication on where hip hop is headed in the city. Development of surrounding businesses, employment opportunities, and crowd attraction are few of the things expected from events in the event management area. Successful initiation and completion of hip-hop events will give Dubai an economic edge against its competitors. Understanding the importance of hip hop and its economic impact could give new life to the study.

The research will focus and investigate three key areas through the analysis of Dubai's hip hop events' importance and impact the city's ability to differentiate 
itself through hip hop events, major artists and audience from the region and also the advantage and other event management and Dubai's economy.

\section{LITERATURE REVIEW}

\subsection{Definition of Hip-Hop}

Hip-hop music, rap music, is a genre created in the United States by inward city African Americans during the 1970s which comprise of adapted cadenced music that generally goes with rapping, a cadenced and rhyming discourse that is chanted (History, 2009). It was created as a major aspect of hip-hop culture, characterized by four key complex components such as MC-ing/rapping, DJing/scratching with turntables, break moving and spray-painting writing. Other components incorporate examining beats or bass lines from records (or integrated beats and sounds) and beatboxing. While frequently used to allude exclusively to rapping, it appropriately signifies the act of the whole culture. The term hip hop music is some of the time utilized synonymously with the term rap music, however rapping is definitely not a required part of hip jump music; the class may likewise consolidate different components of hip hop culture, including DJing, turntablism, scratching, beatboxing, and instrumental tracks (Young, Sinha, Das, \& Wallenfeldt, 2017).

\subsection{Hip Hop in Dubai}

It probably won't be the most effectively refreshing type of music for everybody, except hip hop is as yet carving a swathe through the nation and whatever is left of the Middle East. Regarding open intrigue and neighborhood advancement, it's one of the quickest developing types in the UAE - however, does it have the prominence to make it the complete sound of Dubai?

There is a closeness between the Arabian legacy of verse and hip jump lyricism, however, there's something unique, as well. Address any US example of hip hop, regardless of whether from the east or the west, and they will rapidly reveal to you that it is the music of the minority (Wilkinson, 2009). Hip-hop is more well-known now than it used to be, however, the music has likewise changed significantly. Different experiences are used as motivation to handle various issues that are pertinent to everybody. Many rappers and hip-hop artists are rising from the hip-hop scene in Dubai. There are American artists who perform in Dubai and possibly provide motivation to the community in Dubai.

\subsection{Event Management}

Event Management is a mix of innovative and specialized aptitudes, essential for the creation and conveyance of any live performance or experience (Event Academy, 2018). It requires developing innovation, creativity, energy and other aspects of the audience. Event management is the use of project management to 
the creation and advancement of vast scale events. It includes contemplating the brand, distinguishing the intended interest group, developing the idea, arranging the logistics, and planning the specialized angles for launching the event (BOSS, 2012). Making an effective event requires a considerable measure of diligent work and a different scope of abilities and experience.

\subsection{The Importance of Hip Hop related to Event Management}

To understand hip-hop, it is important to take a view at it as the result of an arrangement of "historical, political, and financial conditions" and to research the role it has as a voice for those impacted by some sort of mistreatment (Blanchard, 1999). This could exemplify to individuals in the Middle East to voice their concern. There's a lot more left to be said in regards to this genre of music, particularly with respect to its complex cadenced interest and dominance of other prosodic developments. In the last 30 years, hip hop culture has expanded and has developed different minds, style, and business.

It can be seen that the event management companies are taking advantage of Hip-Hop growth. Hip-hop artists are part of various events and they are being used to showcase the Dubai brand as well as attract greater audience locally and internationally. Dubai is a city dependent on foreign investment and event management provides an opportunity (Pacione, 2005).

\section{METHODOLOGY}

The methodology that is used by the study has been selected to acquire accurate information and conclusions about the importance of hip-hop events in Dubai, and how it relates to the event management industry. Qualitative research can be described at collecting, analyzing and interpreting data by observing what people do and say. Qualitative research refers to the meanings, definitions, characteristics, symbols, metaphors, and description of things. It is more subjective and uses different methods of collecting information, mainly individual, in-depth interviews and focus groups (Aliuden, n.d.)

The nature of this type of research is exploratory and open-ended. A small number of people are interviewed in depth and or a relatively small number of focus groups are conducted. For the research at hand, a mixed methods version of Qualitative Research that was in part Phenomenology and part Ethnology which led to understand and delve deeper into the culture and experiences of people who would be considered to be veterans of local and grounded Hip-Hop Events. Due to the fact that two of the researchers of this paper are participants and patrons of the local Hip-Hop scene in Dubai, gaining access to individuals, veterans and influencers of the industry, to get further insight into the current state of affairs as well as the limitation and perceptions of the industry as a whole with regard to its culture and location was possible. As such one can interpret that this paper aims to take an analytical approach. 


\section{RESULT AND DISCUSSION}

The findings of the research at hand can be used to assess the effects of hiphop events on event management in Dubai. It can be used as an assessment to see if hip hop events are truly worthwhile and should be given importance to boost the event industry. In addition, the results of this research will help to avoid pitfalls that hip-hop events may undergo when trying to attract an audience. Till date, not many studies have been conducted on this specific subject, which requests further investigation in the future.

While interviewing each of the interviewees a potential idea and perception that seems to be a common thread in the industry is that the Hip-Hop industry locally is a niche that is showing exponential growth thanks to the support of the public and the artists as well. The growth of UAE as a tourism destination is resulting in the inflow of various people from different cultures which is essentially the base of all good Hip-Hop-Diversity. The governments of UAE and the various institutions have in turn recognized that a change is coming where the traditional markets and industries are no longer the mainstream and are slowing becoming the niche while the niche becomes more mainstream resulting in the development of more arts and talent based schools that are supported and accredited by the government and supported by Sheikhs.

DJ Lobito (25 years Veteran DJ in the UAE) and Aeli (a producer from Tunisia/France) stated in the past Hip-Hop events were done underground and it took a lot of planning and money to execute them. Various authorities had to be approached to get licenses to make noise, serve alcohol, organize music events. This bureaucracy was initially seen a deterrent and a pain and resulted in people giving up and yet the Hip-Hop industry has perseverated. With that perseverance an opportunity for change occurs. Right now, prominent startups are dominated by agents of the Hip-Hop industry like the Dukkan Show (a media/podcast team that started to host music and Hip-Hop artists) and that is just one of many new startups which is now thriving thanks to the growth of the hip-hop industry in Dubai.

According to Mohammed A. Hakam (founder of the longest open mic platform in the UAE called Blank Space.), there could be an establishment of a ministry to regulate performers and copyright and licensing authority in the UAE. This, he forecasts after the establishment of the Ministry of Youth has opened up the Youth Hub which is a free platform where people can have meetings and studio sessions as well as other media related events that promote collaboration and is a nonprofit. This is a move that is overseen by Sheik Mohammad and his team who believes that the currently existing systems must be reworked to become more modern and adapt, which can result in a larger form of integration among different people and cultures which is in line with the officially announced year of tolerance in 2019. 
The overall results can be used by different organizations for various reasons. Event Management organizations can make use of this information to form rules and regulations to better serve and support artists when planning an event. In addition, it can be used by government researchers to identify issues and points of interest when formulating laws and regulation for the Hip-Hop scene in Dubai which can prove to add a positive effect for the future of the industry.

\section{CONCLUSION}

Given the issues that plague the industry with regard to hosting and planning events it would be good for artists to unionize to represent them in the department of economic development, this can give the industry a voice to the ministry and government that in the long run could potentially help cut through the bureaucracy and streamline the process resulting in a more defined and positive growth for the industry. This, if done sustainably, may also have a ripple effect that enriches the other sectors of the country (mainly tourism) which is already of major importance to the UAE.

\section{REFERENCE}

Coughlin, L. (2018). Jason Derulo to perform at Global Village next month. Retrieved from http://whatson.ae/dubai/2018/11/jason-derulo-toperform-at- global-village-in-december/

Geronimo, A. (2018). Dubai to accelerate developments in technology, sustainabilityand Al. Retrieved from https://www.tahawultech.com/region/uae/dubai-to-acceleratedevelopments-in- technology-sustainability-and-ai/

Hunt, M. (2018). Parks, squares, alleys: How do we make sure public spaces in the UAE work well for the multicultural communities that live here? Retrieved from https://www.thenational.ae/lifestyle/wellbeing/parkssquares-alleys- how-do-we-make-sure-public-spaces-in-the-uae-workwell-for-the-multicultural- communities-that-live-here-1.797932

Pacione, M. (2005). Dubai. Cities, 22(3), 255-265

Souiden, N., Ladhari, R., \& Chiadmi, N. E. (2017). Destination personality and destination image. Journal of Hospitality and Tourism Management, $32,54-70$

Wilkinson, J. (2009). Hip Hop in Dubai. Retrieved from https://www.timeoutdubai.com/nightlife/features/7060-hip-hop-in-dubai

Young, Sinha, Das, \& Wallenfeldt. (2017). Rap. Retrieved from https://www.britannica.com/art/rap 


\section{External link:}

Aliuden, M. (n.d.). Qualitative and Quantitative Research Retrieved from https://www.academia.edu/4780163/Qualitative_and_Quantitative_Re search

Blanchard, B. (1999). Retrieved from https://web.stanford.edu/class/e297c/poverty_prejudice/mediarace/soc ialsignificance.htm

Hip-hop. (n.d.). Retrieved from https://www.merriam-webster.com/dictionary/hiphop

Hip-Hop is born at a birthday party in the Bronx. (n.d.). Retrieved from https://www.history.com/this-day-in-history/hip-hop-is-born-at-abirthday-party-in- the-bronx

What is Event Management? Explore Events. (2018, August 02). Retrieved from https://eventacademy.com/news/what-is-event-management/

What is an Expo?. (n.d.). Retrieved from https://www.bie-paris.org/site/en/whatis-an-expo 